\title{
Combate entre pizarristas y almagristas en Paisajes peruanos: La Batalla de Chupas vista por Riva Agüero
}

\author{
Zhenia Aparicio Aldana ${ }^{1}$ \\ Recibido: 7 de octubre de 2017 - Aprobado: 27 de octubre de 2017
}

\begin{abstract}
Resumen
En 1912 José de la Riva Agüero y Osma realiza un viaje por el Perú que se extendió desde el Cuzco a Huancayo, transformándose en uno de los primeros peruanos que recorrió el territorio nacional. Como resultado de este viaje, Riva Agüero y Osma escribió un interesante texto titulado Paisajes peruanos. Además de contextualizar la importancia de Riva Agüero y Osma para la historia peruana, en este artículo se analiza el relato contenido en Paisajes peruanos, destacando tanto su reivindicación del pasado colonial como el protagonismo que el autor le entrega al paisaje. Del mismo modo, se pone especial atención a su apreciación de la brutal Batalla de Chupas, en la cual se enfrentaron a muerte pizarristas y almagristas en su lucha por el control de lo que hoy conocemos como Perú.
\end{abstract}

Palabras clave: Perú, Riva Agüero, Paisajes Peruanos, Batalla de Chupas.

\section{The battle between pizarristas and almagristas in Paisajes Peruanos: The battle of Chupas seen by Riva Agüero}

\begin{abstract}
In 1912, José de la Riva Agüero y Osma made a trip through Peru extending from Cuzco to Huancayo, becoming one of the first Peruvians to travel the national territory. As a result of this trip, Riva Agüero y Osma wrote an interesting text called Peruvian Landscapes. In addition to contextualizing the importance of Riva Agüero and Osma for Peruvian history, this article analyzes the story contained in Peruvian Landscapes, highlighting both its vindication of the colonial past and the importance given by the author to the landscape. Likewise, special attention is given to his opinion about the brutal
\end{abstract}

1 Peruana. Magíster en Educación, Magíster en Derecho Público, Estudiante del Programa de Doctorado en Humanidades con mención en Cultura, Universidad de Piura, Perú. Académica, Universidad de Piura, Perú. E-mail: zhenia.aparicio@udep.pe 
Battle of Chupas, in which pizarristas and almagristas fought to death in their battle to control the territory that we know as Peru.

Keywords: Peru, Riva Agüero, Peruvian landscapes, Battle of Chupas.

\title{
Combate entre pizarristas e almagristas em Paisagens Peruanas: A Batalha de Chupas vista por Riva Agüero
}

\begin{abstract}
Resumo
Em 1912, José de la Riva Agüero e Osma faz uma viagem pelo Peru que se estendeu desde o Cuzco a Huancayo, tornando-se num dos primeiros peruanos que percorreu o território nacional. Como resultado desta viagem, Riva Agüero y Osma escreveu um interessante texto chamado Paisagens Peruanas. Além de contextualizar a importância de Riva Agüero e Osma para a história peruana, neste artigo analisa-se o relato contido em Paisagens Peruanas, destacando tanto a sua reivindicação do passado colonial como o protagonismo que 0 autor Ihe entrega à paisagem. Do mesmo modo, se põe especial atenção à sua apreciação da brutal Batalha de Chupas, na qual enfrentaram-se a morte pizarristas e almagristas na sua luta pelo controle do que hoje conhecemos como Peru.
\end{abstract}

Palavras-chave: Peru, Riva Agüero, Paisagens peruanas, Batalha de Chupas.

José de la Riva Agüero es considerado como una figura representante del historicismo peruano del siglo XX. Para Samuel Rivera (2004: 104), "RivaAgüero conserva cierto espacio en la historia de la cultura peruana de su siglo como personalidad intelectual, en parte por la complejidad de su obra le ha permitido sobrevivir en la memoria social en calidad de académico no político, en este caso como iniciador de la historiografía científica republicana y como pionero de la historia de la literatura peruana".

Es catalogado también como un auténtico humanista. Losada y Puga (1944: 282-283), haciendo referencia a su rasgo humanista nos relata que "vuelto al Perú en 1930, pudimos comprobar en él un cambio fundamental. Era siempre el talento deslumbrante, la erudición prodigiosa, la cultura ubérrima a que estábamos habituados, pero había adquirido algo que le faltaba casi por entero cuando emprendió su viaje: había vuelto en lo esencial, pero sólo en lo esencial hasta ese entonces, a la fe católica". Es importante, abordar los aspectos biográficos de este pensador e historiador peruano, en vista a que en él se refleja una "prueba de la capacidad mental de una raza y del vigor y plenitud que laten en el fondo del alma de un pueblo" (Losada y Puga, 1944: 282).

Cuando aún se sentían los rezagos del paso por Chile nace el día 26 de febrero de 1885, don José de la Riva-Agüero y Osma, Marqués de Montea- 
legre de Aulestia, hijo único del matrimonio formado por José Carlos Riva Agüero y Riglos y María de las Mercedes de Osma y Sancho Dávila, procedente de una larga estirpe familiar que lo relacionaba con la alta nobleza hispanoamericana, siendo uno de los últimos representantes sociales de ésta en el Perú del siglo XX, "le sonreía el nacimiento y la fortuna, pues su familia era una de las más adineradas del Perú del 900, y heredaría de ella, en su momento, varias haciendas de nota y una veintena de inmuebles de lo más exclusivo de la Lima que lo vio nacer. Era bisnieto del autoproclamado Primer Presidente de la República durante de guerra civil de 1820-1826, José de la Riva Agüero y Sánchez Boquete, último Marqués de Montealegre de Aulestia en la monarquía peruana" (Rivera, 2004: 105).

Riva Agüero tuvo una prematura y sorprendente madurez de criterio, un niño de suma curiosidad y muy crítico, dejando en algunas ocasiones a muchos absortos por su sorprendente conocimiento a corta edad, "residió en su niñez y juventud temprana en el palacio conocido como de Ramírez de Arellano, sito en la Calle de Lártiga 459, que hoy es el local del Instituto Riva-Agüero, frente a la puerta lateral de la Iglesia de San Agustín. En 1911 se mudó al balneario de Chorrillos, que sería, mutatis mutandis, su residencia el resto de la vida" (Rivera, 2004: 106). Inició sus estudios en el colegio de los Sagrados Corazones, que sacerdotes franceses habían instalado en el antiguo convento o recolección dominicana, por eso se hizo popular con el nombre de la Recoleta; en dicho centro de estudios algunos compañeros veían en Riva Agüero al "niño engreído" a quien acompañaba su criado o era conducido en coche cuando llovía. Era un ávido lector y esto desde muy pequeño, que incluso inventaba males para quedarse en casa regocijado con las lecturas que amaba.

La Recoleta para Riva Agüero fue importante en virtud que desde su ingreso en el recién fundado colegio en 1896, al pensador le inculcaron lecturas: "existe el testimonio de que fue el colegio el que le facilitó la lectura temprana de Juan Donoso Cortés, Marqués de Valdegamas, tan famoso entonces como hoy por su apocalíptico Discurso sobre la Dictadura. Donoso era conocido en el ambiente estudiantil por sus discursos parlamentarios en general, que eran un modelo para la enseñanza de la retórica forense, pero también por su postura contrarrevolucionaria, furibunda contra la Revolución Francesa y el liberalismo. También habría sido el colegio ocasión para leer (o conocer) al Conde Joseph de Maistre (1753-1821), sin duda el pensador más radicalmente anti moderno que gestara la Revolución Francesa" (Rivera, 2004: 106).

Egresó de la Recoleta en 1902, y se matriculó en la facultad de Letras de la Universidad Nacional de San Marcos. En 1905 se graduó como Bachiller en Letras con la tesis "Carácter de la Literatura del Perú Independiente. En 1910 
optó por el grado de Doctor en Letras con la tesis "La Historia en el Perú". En junio de 1912 movido por el solo afán de conocer el Perú, de adentrarse sin reparos en lo peruano, inicia su famoso viaje del Cuzco a Lima siguiendo la ruta de los caminos del inca; producto de esta vivencia, sería su grandioso libro, materia de comentario, titulado Paisajes peruanos, el cual se convirtió en una obra de capital importancia para la cultura peruana.

En 1913 obtuvo el título de abogado y se graduó de doctor en Jurisprudencia con la tesis "Concepto de Derecho". Al estar en un autoexilio por casi once años en Europa, la añoranza a su tierra hizo que retornara y emprendió viaje a tierras peruanas. Aceptó el cargo de alcalde de Lima que le ofreciera David Samanez, desempeñándose como tal entre 1931 y 1932. En una actitud valiente y excepcional el 24 de septiembre de 1933, ante sus antiguos profesores y amigos de la Recoleta, hizo pública "profesión de su fe y retractación de errores". En este momento solemne de su vida recordó a su madre y a su tía: "Reconozco deberlo, por lo que respecta a meros instrumentos humanos, en primer término a las domésticas influencias maternas del piadoso y bendito hogar donde nací" (Jiménez Borja, 1966: 44).

José de la Riva Agüero murió en el hotel Bolívar el 25 de octubre de 1944. Con motivo de su deceso el Mercurio Peruano publicó un homenaje póstumo en el número 213 del mismo año, en donde ilustres pensadores compartieron opiniones acerca de este insigne maestro. En el Mercurio Peruano se sostiene que "sus investigaciones y libros podrán ser superados por el tiempo y las generaciones, su obra intelectual ha podido no ser todo lo extensa y orgánica que le permitían sus excepcionales condiciones, los nuevos tiempos podrán diferir absolutamente de lo que añoraba. Pero quedará siempre, para ejemplo de todos los peruanos que vengan, su amor por el Perú, la lúcida exaltación de nuestros valores, la pasión nacionalista que ennoblece su existencia y la firmeza de sus convicciones, sacrificando por principios ventajosas posiciones, ejemplo de carácter, sin regateos ni acomodos. Y eso permanecerá siempre" (Mercurio Peruano, 1944: 44).

\section{Riva Agüero y sus Paisajes Peruanos}

Puede ser considerado como su obra de juventud, gran legado para la historia y cultura del mundo. Paisajes Peruanos es, sin lugar a dudas, producto de la vivencia de su autor, quien en el año 1912, con solo veintisiete años decidió emprender un viaje distinto al que hacía la juventud intelectual de la época, acostumbrada a ir a Europa y experimentar la vida cosmopolita, viajó de Lima al Cuzco realizando el recorrido de retorno por la sierra, siguiendo el secular camino de los Incas. El autor viajó en ferrocarril y a lomo de mula por esos senderos, conociendo profundamente el Perú. 
La influencia e impresión que le causó dicho viaje quedó registrada en sus Paisajes Peruanos (edición póstuma de 1956), la que se ha constituido en una obra de gran importancia para la cultura peruana, escrito en la plenitud vital de los treinta años y que tiene la madurez innata de los libros primigenios del autor, su energía y entusiasmos moceriles y el intenso peruanismo consustancial con su espíritu y con toda su obra. Va precedido del prólogo escrito por el destacado historiador Raúl Porras Barrenechea. Podemos afirmar que es el primer libro de viajes escrito por un peruano con lo que se constituye como un gran y singular testimonio.

Y decimos testimonio en el sentido de que en Paisajes Peruanos RivaAgüero "describe con erudición y distinguida prosa su recorrido, el entorno natural y la vida de los peruanos del Ande" (Comisión de Promoción para la Exportación y el Turismo - Promperú, 2014: 6). A su vez, el texto es premonitorio, y es que en su contenido se ve el uso racional del medio ambiente, que conlleva a vislumbrar en él, lo que hoy se conoce como desarrollo sostenible. No podemos dejar de mencionar, en este sentido, el inventario de la flora típica de la zona en aquellos tiempos que se contempla en páginas de su libro. Otro punto resaltante del libro, es la manera como Riva Agüero plasma su reflexión histórica; el autor viaja mentalmente al pasado y presente, en donde muestra su interés por el Perú, que hace que nos quede en nuestra memoria el paisaje intacto que plasma en líneas de su libro. Así, señala el mismo Riva Agüero:

"Ha concluido mi peregrinación por las provincias verdaderamente características de nuestra sierra. Antes de que las vías férreas y el comercio moderno realicen la obra necesaria y salvadora de vulgarizarlas y desfigurarlas, he contemplado en su aislamiento y su enternecedora miseria las comarcas que fueron el solar del Perú incaico, la entraña del Perú español, el campo principal y el corazón de la historia patria hasta la mitad de la centuria XIX y que algún día han de volver a serlo. ¿Qué impresiones dominantes me dejan? La de su importancia pasada, la de su decadencia presente, y la del perpetuo contraste entre sus diversas zonas, no menores que las que hay entre toda la misma sierra y las otras dos grandes regiones del país" (Riva Agüero, 2014: 188).

En el prólogo realizado por Raúl Porras Barrenechea podemos encontrar explicaciones de este ilustre escritor, que nos permiten comprender el pensamiento de Riva Agüero en su viaje a la sierra peruana. Así, Porras sostiene: "Riva Agüero fue siempre hombre de gran ser, de instintiva mentalidad rectora, prendado de lo trascendente. En los Paisajes peruanos Riva Agüero continúa su meditación cardinal iniciada en el carácter y en la Historia en el Perú; pero ahora, con más brío y solvencia, aprendidos de la realidad, con vista a un Perú integral". Y prosigue el autor del prólogo: "La visión de la sierra, 
la compenetración con la vida de los pueblos de la sierra y con el hombre andino emboscado en su doble soledad de espacio y de tiempo, transformó fundamentalmente el espíritu de Riva Agüero, le reveló la unidad fundamental entre todas las partes del Perú, forjó su teoría de un Perú integral y sincrético, sin el pecado capital de la división" (Riva Agüero, 1995: XXIX).

Mallqui Caballero y Lau Luis (2012: 90) señalan respecto a esta obra que "Paisajes peruanos, el libro escrito por José de la Riva-Agüero y Osma sobre la base de un viaje que realizó hace exactamente un siglo, marca una pauta importante en el análisis del estudio del paisaje cultural puesto que realiza un estudio más profundo de la conjugación, impacto y simbiosis de lo humano en el paisaje. El relato de sus viajes va más allá de la descripción superficial. En efecto, es un análisis que rompe con el fuerte prejuicio homogeneizador de la sierra, tan acentuado en esa época. El análisis que hace del uso del territorio, la relación de este con la población, las costumbres agrícolas y cómo esto cambia en el tiempo (comparando el pasado inca y colonial con el entonces presente republicano) son elementos presentes a lo largo de su recorrido de Cusco a Huancayo". Basándonos en esta cita, el libro Paisajes peruanos, tiene la característica, además de ser una obra de sumo interesante, de hacer surgir un aprendizaje abundante. A través del mismo se conocen nuevos personajes como la princesa Angelina, hija de Atahualpa, casada con el soldado cronista Juan de Betanzos, quien tradujo tan fielmente los cantares épicos de los indios, o también aprendemos nombres originales de algunos lugares como Uramarca (Río Pampas) y Angoyacu (Río Mantaro). A su vez, Riva Agüero enriquece nuestro vocabulario, otorgando significados a nombres como Pomacocha o laguna del Puma, Vilcashuaman o halcón sagrado, Ayacucho o rincón de los Muertos.

Para José Vasconcelos, Riva Agüero a partir de Paisajes peruanos nos da a entender su gran conocimiento que tiene del Perú, en este sentido destaca que el autor "conoce su Perú palmo a palmo. En sus largos viajes a pie y a caballo, se había aproximado a la gente, habría conversado con los vecinos. De esos "relatos" surgió un libro interesantísimo por sus reflexiones y como documento de la demografía de la época: "Los paisajes peruanos", que tanto acrecentará su fama" (Mercurio Peruano, 1944: 14).

Y es que para Riva Agüero la historia es la vida misma, por eso estudiar la historia es estudiar la vida colectiva, estudiar la historia del propio país es estudiar los fundamentos de la comunidad nacional para comprender el presente. El presente subsiste dentro de la continuidad histórica y es este presente que se transforma en pasado y vive en nosotros formando parte de nuestra realidad. Cada época tiene una entidad, sus límites, caracteres, pero todas ellas solidarias entre sí. El Perú no tiene una forma física: somos nosotros los que le damos forma. Cada generación tiene la tarea de dar forma histórica 
al Perú que se manifiesta a través de nosotros, que le damos existencia real. Perú es realidad histórica que va dando su forma en el acontecer y que reposa sobre la misma tradición.

\section{La Batalla de Chupas vista desde Paisajes peruanos}

\section{a) Antecedentes de la Batalla de Chupas}

Partimos del contenido en Paisajes peruanos, sobre el conjunto de escenarios específicos que evocan sucesos históricos que ahí se llevaron a cabo, suponemos que Riva Agüero contrastaba la información contenida en los libros, en las crónicas que llevaba consigo. Este contraste entre lo contenido en la fuente escrita y lo visto por el autor permite ver la realidad peruana, el contraste que caracteriza al Perú en su cultura y en su pensamiento.

El relato de la Batalla de Chupas, contenida en Paisajes peruanos por Riva Agüero, nos lleva justamente a ese momento histórico de una de las cruzadas más sangrientas de la guerra civil entre conquistadores del Perú en donde los realistas (leales a la Corona Española) y almagristas (rebeldes) se enfrentan, culminando con la captura de Almagro el Mozo, quien fue juzgado y condenado a muerte.

En Chupas desapareció el bando almagrista, que venía en picada tras su frustrada expedición a Chile y que se había enfrascado en un duelo a muerte con los Pizarro. Poco antes, en la Batalla de las Salinas, Hernando Pizarro había derrotado a Diego de Almagro el Viejo y lo había ajusticiado. Como venganza, los almagristas asesinaron a Francisco Pizarro en junio de 1541; proclamaron como gobernador a Almagro el Mozo y desataron una feroz represión contra los partidarios del Marqués, quienes se habían hecho increíblemente ricos en breve tiempo (Zapata, 2011: s/p).

Así, tras el asesinato de Francisco Pizarro a manos de los almagristas, día en que el Marqués Pizarro se defendió de una manera heroica, tal como lo relata José Antonio del Busto, en su obra Francisco Pizarro - El Marqués gobernador (Del Busto, 1993: 213 y ss): "El bravo viejo se defendía como un león" y citando a Gómara, "luchaba esgrimiendo la espada con tal destreza, que ninguno se acercaba, por valiente que fuese". A pesar de ello, sus esfuerzos no valieron mucho, y sus verdugos abandonaron la vivienda al grito de "El tirano ha muerto", propagándose la noticia por todo el territorio.

Ante la caída del Marqués, los almagristas convirtieron a Diego de Almagro el Mozo, bastardo mestizo del adelantado Almagro el viejo, en Gobernador del Perú. Sucedido este hecho y ante la existencia de revueltas en el territorio peruano, se anunció en ese mismo año la llegada del juez visitador Cristóbal 
Vaca de Castro, enviado por la Corona Española para pacificar el Perú. A raíz de esta visita, Almagro el Mozo y los suyos abandonaron Lima y se adentraron a la sierra peruana con el fin de organizar la resistencia contra Vaca de Castro.

Posteriormente, en el año 1542, y basándonos en la correspondencia entre Almagro el Mozo y Vaca de Castro, el primero exigía que se le reconociera la gobernación de Nueva Toledo; por su parte, Vaca de Castro rechazó tal exigencia lo que provocó, además de otras diferencias, que Almagro el Mozo se convenciera que las negociaciones no llegarían a mucho y que su única solución eran las armas.

El 13 de septiembre de 1542 Almagro el Mozo y sus tropas abandonaron Vilcashuamán. Al día siguiente llegaron a Pomacocha donde descansaron y luego pasaron a Sachabamba donde pasaron la noche. Cerca, a un día de viaje de esa época, se hallaba el campo de Chupas, situado cerca de Huamanga en la actual región de Ayacucho.

El 16 de septiembre de 1542 comenzó la lucha en Chupas. El enfrentamiento fue cruel y largo. Cristóbal Vaca de Castro, tras muchas bajas en ambos bandos, logró la victoria. Diego de Almagro fue apresado y condenado a muerte con garrote. Vaca de Castro asumió el gobierno del territorio e inició la pacificación del territorio (Vargas Ugarte, 1966: 172).

\section{b) La batalla de Chupas en Paisajes peruanos}

Ya analizando el relato que nos da Riva Agüero, éste nos presenta en Paisajes peruanos el llano de Chupas como un "campo histórico" en donde se desarrolló el porfiado combate de 1542; incluso Riva Agüero, hace mención a su anhelo de conocer y de evocar aquel famoso encuentro en que la flor de los conquistadores, tratando de dar a conocer quizás que en ese momento se encontraban los más resaltantes y significativos personajes de la conquista del Perú, vengó la muerte del Marqués Pizarro.

Asimismo dentro del preámbulo para iniciar el relato histórico de la Batalla de Chupas, el historiador hace una comparación: "Las minúsculas batallas de nuestro S. XVI eran mucho más épicas que las gigantescas guerras de la Europa moderna; porque el predominio de las nobles armas blancas y de la caballería, y la misma pequeñez de los contingentes, daban a la lucha el carácter de la individualidad poética, que desaparece del todo en las confusas acciones contemporáneas" (Riva Agüero, 1995: 98).

Y es que realmente la Batalla de Chupas, a través de la visión de Riva Agüero, se muestra como un evento glorioso, legendario y heroico. La razón es que el carácter individual de sus combatientes, es resaltado de una manera singular, rescatándose verdaderos héroes de batalla; los cuales conforme al 
historiador, habían participado en la batalla de Rávena, acontecida 30 años antes en Italia, la cual se caracteriza por ser colosal y a la vez cruenta y feroz. Ahí, los directores y combatientes de Chupas actuaron, pero no gozaron de tanta individualidad y protagonismo como sí lo vivieron en el llano ayacuchano.

Riva Agüero, empezando el relato de la batalla, a la cual Raúl Porras Barrenechea considera como una de sus mejores páginas de evocación histórica (Riva Agüero, 1995: XLVII), hace mención a la decisión de la hueste real comandada por Vaca de Castro de detenerse en el llano de Chupas, y esto porque divisaron en las pampas frente a las lomas, el ejército almagrista el cual estaba acompañado por el enjambre de los indios auxiliares del Inca Paullu, "fiel a la memoria de su difunto amigo, el Adelantado". Pero ¿a qué personaje histórico se refiere Riva Agüero con el "Adelantado"? Ya lo hemos mencionado en líneas anteriores, sin embargo, empecemos con el Inca Paullu, el cual fue un príncipe inca, aliado de los españoles, hijo de Huayna Cápac y de Añas Colque.

Este inca fue medio hermano de Huáscar, Atahualpa y Manco Inca. Acompañó a Diego de Almagro, socio de Francisco Pizarro, en la fallida expedición de la conquista a Chile en 1535, el adelantado es Diego de Almagro, siendo esta denominación referida a un alto dignatario español que llevaba a cabo o adelante una empresa jurídico-militar y civil por mandato, cuenta y bajo designio real.

Esta mención a Diego de Almagro no sólo la encontramos en Riva Agüero, revisando las crónicas que se presume que el historiador leyó y analizó, lo cual aclara en la introducción del relato donde el autor señala: "Acababa yo de releer en el Cuzco algunas crónicas de la Conquista, que llevé conmigo para ilustración de mi itinerario y entretenimiento de los ocios de viaje". Encontramos entonces en la Crónica "Descubrimiento y Conquista de la Provincia del Perú" de Agustín de Zarate lo siguiente, "sucedió la muerte del Marques (...) por lo cual Don Alonso y los que no habían sido en ella se quedaron con Vaca de Castro, siguiéndole y acompañándole hasta que venció a don Diego de Almagro el Mozo, en la batalla que le dio en el valle de Chupas, donde se halló en acompañamiento del estandarte real del mismo don Alonso y otros que fueron aficionados al Adelantado".

Dejando al adelantado Diego de Almagro, Riva Agüero posteriormente indica los personajes sobresalientes de la batalla. En el lado realista menciona a Garcilaso de la Vega padre, a Don Alonso de Alvarado, el conquistador de los grandes bosques de Chachapoyas, el Maestre de Campo don Gómez Tordoya de Vargas, entre otros.

Riva Agüero, en su relato, no podía dejar de lado al cronista mestizo Inca Garcilaso de la Vega como fuente de su relato, y es que el historiador a 
través de su "Elogio al cronista mestizo" lo considera "como la rica fuente de la que brotan las puras esencias de la nueva nación americana". Para Riva Agüero, "Si Garcilaso es mestizo por la sangre lo es también, y más aún, por la cultura" (Guillermo Sosa, 1962: 45). Y decimos fuente porque al consultar los Comentarios Reales de los Incas en su segunda parte, encontramos la referencia a la batalla de Chupas y a sus participantes. Así, el Inca señala: "El Gobernador puso la gente en su escuadrón. A la mano derecha de la infantería puso el estandarte real, que iba a cargo de Alonso de Alvarado, y el alférez era Cristóbal Barrientos, natural de Ciudad Rodrigo, vecino de Trujillo, donde tenía repartimiento de indios. Pedro Álvarez Holguín y Gómez de Alvarado, Garcilaso de la Vega y Pedro Anzúrez, capitanes de caballo" (Garcilaso de la Vega, 2008: 424).

Conforme al contenido de la narración, la picardía y habilidad de Riva Agüero de mantenernos en el hecho histórico de la Batalla de Chupas, nos permite conocer las debilidades de infantería de la hueste real, y esto en vista a que el autor menciona que "tanto Gómez de Tordoya como Per Álvarez Holguín se habían ataviado como para un torneo, con chaperías de oro sobre las armaduras y encima ropillas acuchilladas de damasco blanco; lo cual fue causa de la muerte de ambos, pues quedaron muy señalados a los tiros del enemigo" (Riva Agüero, 1995: 101). Y es que realmente, si nos imaginamos esa escena, podremos ver dos ataviados y relucientes combatientes que se convierten en puntos de ataque masivo de las huestes almagristas.

Por su parte, los almagristas, conforme lo señala Riva Agüero, poseían una artillería fuerte, lo cual constituía una indudable ventaja para los rebeldes, lo que es también consignado por Agustín de Zárate (1853: 504), relatado en las crónicas: "Vaca de Castro envió al capitán Castro con cincuenta arcabuceros, que con ellos trabase escaramuza en tanto que las banderas subían por unos recuestos que habían de pasar con gran temor, porque si don Diego revolviera les hiciera muy gran daño con la artillería, porque allí descansó toda la infantería".

Esta artillería almagrista la comandaba Pedro de Candia, el cual al conocer su poderío se dirige a Diego de Almagro y le proclama: "Vuesa Señoría tiene su escuadrón puesto y ordenado con tantas ventajas de sitio, de artillería, que sin encuentro de lanza ni golpe de espada tiene vencidos sus enemigos, sólo con estarse quedo y no moverse de como ésta. Que por cualquier parte que sus contrarios vengan, los desbarata y los hace pedazos con su artillería antes que lleguen a tiro de arcabuz" (Garcilaso de la Vega, 2008: 425).

Vaca de Castro dispuso su ejército con un arte que admiró a sus veteranos, los cuales no podían comprender cómo un hombre, cuya vida había sido consagrada al estudio, conocía tan bien la táctica militar. Así, Álvarez de Holguín y Garcilaso de la Vega mandaban las dos alas, Alonso de Alvarado llevaba 
el estandarte real y Nuño de Castro conducía la vanguardia, compuesta de una compañía de mosqueteros escogidos: el gobernador quiso al principio ocupar este puesto, mas cediendo a las amonestaciones de sus capitanes, se quedó en la reserva con treinta de sus mejores jinetes. Estaba para ponerse el sol, cuando empezó el combate.

La relación entre la masa indígena y los españoles se demuestra claramente en la Batalla de Chupas, vista desde Riva Agüero, así argumentando el historiador, basándose en la crónica del Perú de Cieza de León, señala: "Las indias principales, que los jefes y guerreros de ambos campos llevaban como mancebas, atronaban con alaridos de pavor las vecinas alturas y se mesaban desesperadas los cabellos, presintiendo la matanza de sus amos, y para ellas el desvalimiento y las violencias posteriores. Al contrario, los indios de carga, que los dos ejércitos traían para conducir la artillería, bagajes y bastimentos hasta los de guerra, cuzqueños que con Paullu ayudaban a Almagro y chachapoyanos que servían de Alonso de Alvarado y Vaca de Castro, aullaban de gozo y daban gracias al Sol, que les permitía presenciar la mutua destrucción de sus vencedores" (Riva Agüero, 1995: 113).

Lo que pasó entre los chachapoyanos con los españoles es un punto en la historia muy mencionada. No olvidemos que en 1536, los incas liderados por Manco Inca, se rebelaron contra los españoles en el Cuzco. Tiempo después, relatando este levantamiento, Titu Cusi Yupanqui, hijo de Manco Inca, escribió: "Fue esta batalla de una parte y de otra, ensangrentada por la mucha gente de indios que favorecían a los españoles, entre los cuales estaban dos hermanos de mi padre, llamados el uno Inguill y el otro Vaipai, con mucha gente de su bando y Chachapoyas y Cañares." (Schjellerup, 2005: 143). En tiempo posterior a la muerte del Marqués Pizarro, Alonso de Alvarado, quien representaba a la provincia de Chachapoyas, tomó partido por la corona española. En 1542 partió de Chachapoyas con algunos nativos para tomar parte de la Batalla de Chupas, en Ayacucho.

Ya hemos hecho referencia al Inca Paullu y su relación con los almagristas. Teniendo en cuenta este dato, Riva Agüero caracteriza a los indios de este lado como fieros y aguerridos, superiores a los chachapoyanos: "Al mismo tiempo, los indios de Paullu, enardecidos, atacaban por la izquierda, con una lluvia de piedras y varas. Fue el momento crítico para los realistas. Insuficientes para los de Paullu los auxiliares de Chachapoyas, hubo que destacar contra aquellos un grupo de arcabuceros, que los deshicieron con sus descargas" (Riva Agüero, 1995: 104).

A su vez Riva Agüero nos relata el estado caótico y de desesperación de las indias al ver a sus amos en batalla. Ya hemos hecho mención que las indias principales, que los jefes y guerreros de ambos campos llevaban como mancebas, atronaban con alaridos de pavor las vecinas alturas. $Y$ es que 
conforme a Cieza de León esta conducta era una costumbre en el ámbito indígena, ya que el mismo al referirse a la hermosa tierra de Cajamarca y de sus incas señores de este reino, en donde aprisionaron a Atabaliba: "Los naturales señores de esta provincia fueron muy obedecidos de sus indios y tenían muchas mujeres. La una de las cuales era la más principal, cuyo hijo, si lo había, sucedía en el señorío. Y cuando fallecía (...) hacíanse en estos tiempos grandes lloros contínuos" (Cieza de León, Zárate y De Jerez, 1946: 628).

Costumbre indígena que confluye con la llegada de los conquistadores, y es que en cada relato de Paisajes peruanos, se muestra esa compenetración con la vida de los pueblos de la sierra y con el hombre andino emboscado en su doble soledad de espacio y de tiempo. Riva Agüero, con su certero instinto histórico y su poderoso sentido evocativo, tal como lo señala Raúl Porras Barrenechea en el prólogo del libro, nos muestra que los indios participantes agradecen al dios sol por ver a sus vencedores destruirse en batalla. Esta evocación es realmente lúcida y a la vez un recuerdo que se plasma en la realidad peruana que nos lleva a una meditación del sentimiento indígena ante los vencedores y conquistadores de su tierra. Es que Riva Agüero evoca la conquista en la Batalla de Chupas, recogiendo en su relato la animación bélica de los cronistas, el conocimiento del antiguo arte de la milicia indiana y europea.

La traición está presente en la historia, desde los relatos bíblicos como el de Caín y Abel, o la traición hacia el Cesar. Y es que en la batalla de Chupas también la encontramos en Pedro de Candia, almagrista solo de voz. Así, Riva Agüero (1995: 113) nos cuenta: "cuando rompió sus fuegos la artillería de Candia, más por impericia o traición, los tiros no daban en el blanco, yendo muy por arriba, mientras que los arcabuceros de Francisco de Carbajal, traspuestas las lomas, avanzaban por terreno raso. Indignado el joven Almagro y convencido de la felonía de Candia, corrió hacia él gritándole: ¡Traidor!, ¿por qué me has vendido?, y lo cosió a lanzada, dejándolo expirante sobre sus mismas piezas".

La traición de Candia no es ajena a los cronistas y es que Garcilaso (2008: 426) también la comenta: "Pasado de la loma, salió a campo raso, donde iban en manifiesto peligro de la artillería; mas Pedro de Candia, que era capitán de ella, tiraba por alto, de manera que ningún daño les hacía. Lo cual visto por Don Diego, arremetió con él y a lanzadas lo mató sobre la misma artillería. Y saltando del caballo abajo, con el enojo y rabia de la traición que su capitán le hacía, subió de pies sobre una de las piezas hacia la boca del cañón y con el peso del cuerpo la bajó de punto y mandó pegarle fuego, estando él encima, y metió la pelota en el escuadrón de Vaca de Castro y lo abrió dende la vanguardia hasta la retaguardia..", el Inca, posterior a este 
relato, da una aseveración importante de la conducta de Candia: "pero por la traición de su capitán la perdió". Y es que no olvidemos que Candia era el capitán de la artillería almagrista, la que fue vanagloriada momentos antes de la batalla por el mismo Candia, dándole confianza a Diego de Almagro el mozo de su presunta victoria.

¿Por qué Pedro de Candia cometió traición? Ni Cieza, ni Zárate, cronistas de la conquista, mencionan con exactitud dicho hecho, sin embargo, argumentando en base a lo señalado por el Inca Garcilaso de la Vega, la traición se explica en que en vista a que Hernando Pizarro se encontraba preso en España por agraviar al Marqués, las ansias de poder de Candia hizo dirigir sus pretensiones al ejército realista, el cual tenía el apoyo de España y de su majestad. Y en vista de esto, mandó información secreta a Vaca de Castro aseverándole no temer a la artillería almagrista y al tener esa aseveración, se inicia la Batalla de Chupas, sin embargo, Candia nunca logró las pretensiones de poder anheladas, resultando muerto en el fragor bélico.

Al relatar la batalla, Riva Agüero no deja de lado aquellos aspectos que en cierta manera de la lectura pueden ser catalogados como anecdóticos. Uno de ellos es el que le sucedió al obeso Francisco de Carbajal, el cual para animar a su gente, "arrojó la cota de malla y la celada, y quedándose en cuerpo, vestido con un jubón de lienzo, y con una partesana en la mano, se puso a la cabeza de la columna gritando: 'Adelante caballeros. Miradme cuan grueso soy, y voy sin tenerles miedo'".

Este hecho nos muestra al valeroso Francisco de Carbajal, el cual no teniendo miedo al ejército almagrista proclama que su gordura es doble valor, alentando así a los realistas temerosos ante la aguerrida milicia de los de Almagro; esto porque los estragos causados por los cañones enemigos, hicieron que se lance al ataque a pie, alentando a voces a los suyos. Esta arenga de Francisco, hizo que la tropa se vea entusiasmada al ejemplo de su corpulento y obeso capitán, apoderándose con su valerosa acción de la artillería de Almagro.

En el transcurso de la batalla, se escuchaban los gritos de ¡Santiago el Rey y Pachacámac!, a los que los de Almagro respondían con los de ¡Santiago, el Rey, Almagro y Chile! Garcilaso respecto a estas proclamas nos dice que "los unos y los otros pelearon tan obstinadamente que, aunque el sol era ya puesto y la noche cerrada, no dejaban de pelear, sin conocerse los unos a los otros más de por el apellido, que los unos decían ¡Chili! y los otros ¡Pachacamac!, en lugar de Pizarros y Almagros, que también alcanzaron estos renombres aquellos bandos." (Garcilaso de la Vega, 2008: 429). El significado de las arengas demuestra las hazañas de los conquistadores hechas años atrás por parte del Marqués Pizarro, conquistador del imperio de los incas, y, por otro, Diego de Almagro, el conquistador de Chile. 
A medida que la batalla continuaba cayeron heridos mortalmente el Maestre de Campo D. Gómez de Tordoya y el Capitán de delanteros Nuño de Castro; perdió el brazo García Melo; y otra pelota de arcabuz derribó, con todas las muelas rotas, a Alonso de Loayza, el hermano del Arzobispo. Pronto, señala Riva Agüero (1995: 106), se quebraron casi todas las lanzas, con muchos muertos y caídos de ambas partes, y entonces echaron mano a las espadas, porras y hachas; empleando todo, arreció la lucha con las acometidas de los piqueros. Y es que entre los incidentes de la batalla, así como hemos mencionado actos de valentía y de traición; la cobardía estaba vista a todas luces. Así, el autor relata: "Entre los lances de heroísmo no faltaron casos de flaqueza y cobardía, como el de aquel caballero, ilustre en sangre y menguado de bríos, de que trata Garcilaso, el cual, dando por razón haber sido buen amigo del Adelantado Almagro el Viejo, se apartó de la batalla y se cobijó a un lado, entre el hidalgo enfermo y el clérigo Luque (...) y como el mancebo de que hablan Cieza y Zarate, que oculto entre las peñas, murió miserablemente de una bala de arcabuz que en ellas rebotó" (Riva Agüero, 1995:116-117).

La batalla de Chupas es considerada como una de las más sangrientas, la cual conforme a las crónicas duró casi todo un día de cruenta lucha. Garcilaso (2008: 429) nos informa que "era ya más de dos horas de noche, y todavía duraba la cruel pelea, habiendo cuatro horas que se había empezado". Al mismo tiempo que cruenta, la batalla era de resultado incierto. En un primer momento, la victoria estaba para los almagristas, sin embargo, al transcurrir las horas, y ante las bajas en la artillería de Diego Almagro el Mozo, los almagristas se dieron a la fuga. Pero los acérrimos asesinos del Marqués Pizarro obstinados gritaban ¡Ea, a mí, que maté al Marqués!, con el fin de seguir con la venganza hasta las últimas consecuencias. Sin embargo, los soldados ya vencidos trataban de cambiar sus divisas con las de los muertos y heridos realistas.

Al final, la suerte estaba echada, los almagristas estaban vencidos, Diego de Almagro huyó al Cuzco seguido de Diego Méndez, hermano de Orgoñez, el antiguo Maestre de Campo de su padre, y de cuatro o seis amigos más. El pobre mozo Almagro, el mejor mestizo que ha nacido en las Indias, según Garcilaso, muy virtuoso, entendido y valiente, según Cieza, huía a todo correr al Cuzco, camino de su perdición, y es que con tan solo veinte años fue capturado y puesto prisionero en la ciudad imperial por el ejército realista. Allí se le procesó y se le condenó a muerte. Después de confesado y comulgado, Almagro el Mozo marchó al patíbulo con serenidad ante el grito de algunos que lo llamaban traidor; su última petición fue ser enterrado junto a su padre, lo que se aceptó. 


\section{Reflexiones finales}

Para concluir no podemos dejar de mencionar lo dicho por Riva Agüero al término del relato de la Batalla de Chupas: "En el propio campo de Chupas, sepulcro de tantos conquistadores y guerreros, no se construyó iglesia como en el de Salinas del Cuzco; sino un vulgar tambo, que era la primera jornada entre Huamanga y Vilcas. Andando los tiempos, esos llanos y collados se sembraron trigo y formaron una extensa hacienda de panllevar".

La Batalla de Chupas fue feroz, sangrienta y cruel, lo importante en el relato realizado por Riva Agüero es que nos muestra un hecho histórico, basado en principio en la recopilación de crónicas de la conquista, de una manera evocativa y con un sentido animador de los viejos escenarios históricos. Y es que como lo señala Raúl Porras Barrenechea: "En cada paisaje humanizado y vitalizado por la historia, el viajero recuerda una hora o un momento que marcó el azar del Perú", es decir, el relato sobre la batalla de Chupas no es solo un recuento de lo que sucedió sino que ese relato nos lleva a meditar sobre el Perú, en él conocemos sobre la animación bélica de los cronistas, el conocimiento del antiguo arte de la milicia indiana y europea, la frescura popular de las coplas y los parlamentos entre los combatientes que tienen rudeza primitiva, y sobre todo nos lleva a querer conocer el Perú, lo cual nos conduce a ser más cultos como personas y como sociedad.

\section{Referencias bibliográficas}

\section{Fuentes primarias}

\section{a) Periódicos}

Mercurio Peruano (30-X-1944). Edición Especial - José de la Riva Agüero. La Crónica, p. 14.

\section{Fuentes secundarias}

\section{a) Artículos}

Losada y Puga, C. (1944). "José de la Riva Agüero", en Revista de la Universidad Católica del Perú, pp. 282-297.

Mallqui Caballero, C., y Lau Luis, D. (2012). "A cien años de Paisajes peruanos: La importancia del paisaje en la actualidad", en Espacio y Desarrollo, № 24, pp. 89-96. 
Samuel Rivera, V. (2004). "El Marqués de Montealegre de Aulestia: Hermeneuta de la contrarrevolución", en Solar, № 04, pp. 103-137.

\section{b) Libros}

Cieza de León, P., Zarate , A., y De Jerez, F. (1946). Crónica de la Conquista del Perú. México: Editorial Nueva España.

Comisión de Promoción para la Exportación y el Turismo - Promperú (2014). La ruta Riva Agüero - Rutas Literarias. Lima: PROMPERU.

Del Busto, J. A. (1993). Francisco Pizarro - El Márques Gobernador. Lima: Brasa. Elias Lequernaqué, P. (1994). Vida y obra de un Egregio Peruano: Don José de la Riva Agüero y Osma. Piura: Udep.

Garcilaso de la Vega, I. (2008). Segunda parte de los Comentarios reales de los Incas. Lima: Universidad Inca Garcilaso de la Vega.

Guillermo Sosa, J. (1962). En busca del Perú - Serie de temas del Perú contemporáneo. Lima: Ediciones del Sol.

Jiménez Borja, J. (1966). José de la Riva Agüero. V.40. Lima: Editorial Universitaria.

Riva Agüero, J. (2014). Paisajes Peruanos. En C. D. Promperú, La Ruta Riva Agüero - Rutas Literarias. Lima: Promperu.

Riva Agüero, J. (1995). Paisajes Peruanos. Prólogo Raúl Porras Barrenechea. Lima: Pontificia Universidad Católica del Perú.

Schjellerup, I. (2005). Incas y españoles en la conquista de los chachapoya. Lima: Fondo Editorial de la Pontificia Universidad Católica del Perú.

Vargas Ugarte, R. (1966). Historia general del Perú. T.I. Lima: Carlos Milla Batres.

\section{c) Otros}

Zapata, A. (4-X-2011). Clío - Historia y actualidad del Perú y del Mundo, en http://clioperu.blogspot.pe/2011/10/batalla-de-chupas-diego-de-almagro-el. html. Revisado el 02-X-2017. 